\title{
O MOVIMENTO ESCOLA SEM PARTIDO E A POPULARIZAÇÃO DO ÓDIO AOS DOCENTES
}

The Movement "Escola Sem Partido" and the popularization of hate to teachers in Brazil

\author{
Neide Celia Ferreira BARROS \\ Instituto Federal de Goiás, Goiânia-GO, Brasil \\ neidecelia@gmail.com \\ ORCID 0000-0001-9336-0168
}

A lista completa com informações dos autores está no final do artigo

\begin{abstract}
RESUMO
O presente trabalho visa analisar o Movimento Escola Sem Partido e suas proposituras de leis juntamente com suas mobilizações populares através de distorções da realidade e como toda essa trajetória cria um sistema de violência e ódio aos professores, causando medo e sensação de insegurança na classe docente. Discute também a falta de bases legais para o projeto e o conceito de liberdade de cátedra a partir da análise de teóricos da educação e de legisladores. Utilizo como método a análise de artigos em jornais, vídeos de sátiras e entrevistas, assim como diversas fontes Legais (Constituição Federal, Lei de Diretrizes e Bases e Tratados de Direitos Humanos).
\end{abstract}

PALAVRAS-CHAVE: Escola Sem Partido. Democracia. Trabalho Docente.

\section{ABSTRACT}

The present work aims to analyze the Movimento Escola Sem Partido (School Without Party Movement) and its propositions of laws along with popular mobilizations through distortions of reality and how this whole trajectory creates a system of violence and hatred towards teachers, causing fear and a sense of insecurity in the teaching class. It also discusses the lack of legal bases for the project and the concept of teaching freedom from the analysis of education theorists and legislators. I use as a method the analysis of newspapers articles, satire videos and interviews as well as several Legal sources (Federal Constitution, Law of Guidelines and Bases and Human Rights Treaties).

KEYWORDS: School without party. Democracy. Teaching Work. 


\section{INTRODUÇÃO}

No esquete Escola sem partido ${ }^{1}$ - da produtora e canal do Youtube Porta dos Fundos - uma professora de História tenta abordar o conteúdo sobre Escravidão. Ela aparentemente muito constrangida e tensa, busca de todas as formas não ser enfática e se desvia de emitir uma opinião crítica sobre tal prática social. Do outro lado, alunos com equipamentos de alta qualidade de filmagem (simulando um set de uma produção sofisticada) tenta conduzir que ela fale algo se posicionando sobre o tema para que eles possam publicá-la na internet. Ela percebe a armadilha e diz que não vai falar nada pois não quer ser demitida como o professor de Biologia que ensinou o conteúdo "Sistema Reprodutor". A ironia da cena envolve o fato de que professores não podem cumprir seus papeis de educadores e emissários do conhecimento científico devido um linchamento virtual vindo de pressões de pais, da comunidade e equipe diretiva. No caso do vídeo, uma professora, mulher negra, é impelida a falar que há um "lado bom na escravidão" para não receber retaliação e perseguição que poderá afetar sua vida pessoal e profissional, como por exemplo a sua demissão. Este vídeo foi publicado em abril de 2019, e um ano depois, na presente data, já conta com mais de um milhão e setecentas mil visualizações e em torno de oito mil comentários.

Como dito, a publicação deste vídeo ironiza a perseguição a professores e coloca em pauta o debate sobre o amedrontamento dos docentes e o ataque à liberdade de cátedra garantida pela Constituição brasileira. Neste artigo trabalharemos tais temas, buscando nos aprofundar sobre o contexto destas práticas, analisando ponto a ponto o significado destas para a construção da educação brasileira e para o Estado Democrático.

Neste trabalho, dividido em quatro tópicos, apresentaremos no dois uma análise do crescimento do Movimentos Escola Sem Partido (MESP) em meio ao fortalecimento do conservadorismo no país, e quais mecanismos utilizaram para se estruturar. Trataremos também de como tal movimento criou ataques diretos a classe de professores colocandoos como inimigos públicos e espalhando notícias que inspiravam ódio e desprezo da população para com os docentes. E por fim, em um terceiro tópico refletiremos qual é a função da educação e o real papel dos professores a partir das lógicas internacionais de Direitos Humanos e pela Constituição Federal. Trazendo assim uma reflexão sobre o

1 ESCOLA SEM PARTIDO, 2019. 1 vídeo (2min). Publicado pelo canal Porta dos Fundos. Disponível em: < https://www.youtube.com/watch?v=tNxCmR5OWe8>. Acesso em: 25 ago. 2021. 
Movimento Escola Sem Partido e seus claros ataques à liberdade de expressão, aos professores e a uma educação em busca democrática.

\section{MOVIMENTO “ESCOLA SEM PARTIDO” E OS DOCENTES COMO INIMIGOS PÚBLICOS}

Para refletir sobre os movimentos de intervenção na liberdade do professor em sala de aula, o crescimento do Movimento Escola Sem Partido e o peso destes na prática dos docentes brasileiros precisamos entender a escola como um campo de disputa discursivo e de estruturação do poder. Mas primeiramente, antes de uma análise mais precisa sobre esta perspectiva, é necessário entender o contexto da política atual e como a educação se situa neste interim.

Para Vladimir Safatle (2018, p.2-3) o Brasil testemunhou nos últimos anos uma radicalização da Direita, e que o encontro de diversos interesses, como o da burguesia brasileira, liberal e classista, e os pensamentos religiosos fundamentalistas, somados aos valores conservadores deram origem ao que a socióloga Camila Rocha (2018, p.55-63) chamou de "Nova Direita". Luís Felipe Miguel diz que está ascensão se deve a três grupos principais: Os Libertarianistas, seguidores da Escola Austríaca ${ }^{2}$, os Fundamentalistas Religiosos, em sua maioria evangélicos neopentecostais, e por fim os Anticomunistas/Antipetistas (2018, p.19-25). Apesar de nenhum destes autores não se referirem ao termo Neoconservador imediatamente, pensamos ser importante destacá-lo nesta introdução por entendermos que há entre eles um alinhamento muito vivo.

O Neoconservadorismo é um conjunto de ideias surgidas nos Estados Unidos no final dos anos 1960, tendo como destaque o pensador norte-americano Irving Kristol. Ao contrário do Conservadorismo tradicional dos séculos anteriores que atacavam o Liberalismo, estes pensadores entendiam-se como liberais na economia e conservadores na moral. Como tais pensamentos nasceram no contexto do pós-Guerra, período no qual havia uma ebulição de pensamentos e mudanças, os neoconservadores se propunham a serem combatentes imediatos de movimentos sociais que quebravam os padrões estabelecidos (Hippies, Feministas, Movimento Negro e etc.), do Estado do bem-estar social (difundido na Europa), e acima de tudo, do Comunismo (dentro e fora dos Estados

\footnotetext{
2 "Prega que o menor estado possível e afirma que qualquer situação que nasça do mecanismo do mercado é justa" (MIGUEL, 2018, p.16)
} 
Unidos). Apesar de ter sido tido como morto com o final da Guerra Fria e com a queda do muro de Berlim, o Neoconservadorismo voltou à tona no governo de Bush Jr., após o ataque do World Trade Center, em 2001, com políticas de combate a um inimigo externo (TEIXEIRA, 2007, p.20) e foi grande catalisador da Nova Direita que ganharia força quase duas décadas depois em todo o mundo, incluindo o Brasil, através de Olavo de Carvalho ${ }^{3}$, que apesar de negar ser um Neoconservador, traz em seu discurso um misto dos vários pensamentos, que inclui as noções de Kristol e seus companheiros. Desta forma, como já dito acima, com base em valores neoconservadores, percebemos que há uma orientação da Nova Direita combativa em diversas frentes, dentre elas a educação. E um dos principais braços desta agenda é o Movimento Escola Sem Partido - a partir de agora denominado por nós como MESP.

A primeira vez que este movimento ganhou repercussão nacional foi em 2014 na elaboração do Plano Nacional de Educação quando a mobilização de diversas entidades religiosas, políticas e o MESP conseguiram barrar da Lei 13.005/2014 o termo "Gênero". Dali em diante, cada vez mais, o movimento ganhou força, e se tornou mais visível como uma das ramificações da crescente onda que tomava as ruas e se fortalecia na crise política e econômica já estabelecida. (REIS \& EGGERT, 2017, p.9-26)

O Movimento Escola Sem Partido já existia, no entanto, desde o ano de 2004, coordenado pelo advogado Miguel Nagib. Todavia sua repercussão ganhou força com o crescimento de movimentos de Direita/Neoconservadores que catapultaram o discurso da "doutrinação ideológica" no ensino como justificativa para a presença de uma esquerda política no Brasil.

Em entrevista para o programa "The Noite" do canal de televisão SBT, na data de 09/08/2016 Nagib afirmou:

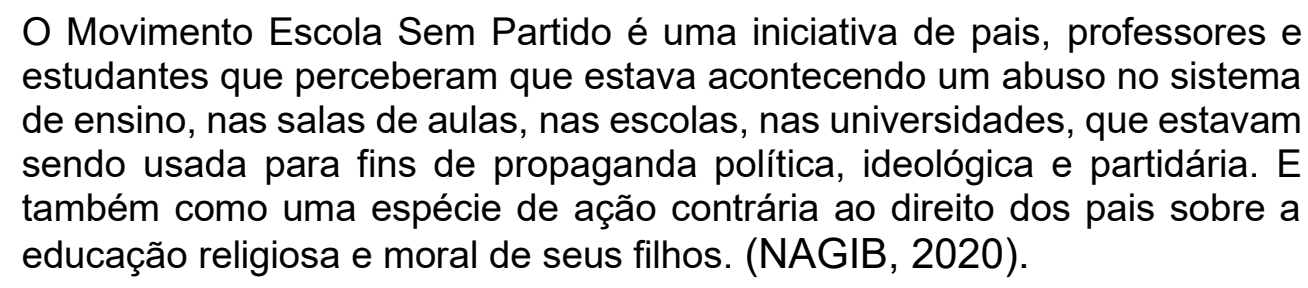

Nagib na mesma entrevista afirmou ainda que há uma "doutrinação ideológica" que em outras palavras, é para ele a “ação pela qual um professor tenta 'fazer a cabeça' de seu aluno". Segundo o advogado há uma retroalimentação ideológica: professores são

\footnotetext{
${ }^{3}$ Olavo de Carvalho atualmente é um dos principais nomes de influência na política da educação brasileira, sendo o responsável por indicar dois ministros da educação: Ricardo Vélez e Abraham Weintraub.
} 
doutrinados nas universidades e voltam como doutrinadores para a educação básica. Assim, o professor é ao mesmo tempo vítima e algoz no sistema educacional.

A base para esses pensamentos vem em sua maioria das obras do escritor Olavo de Carvalho, do qual Nagib já se declarou "leitor e fã"4 e sua argumentação de que há um projeto de implementação de um chamado "Marxismo Cultural". Este autor, inúmeras vezes já salientou publicamente que acredita haver uma "doutrinação comunista" em todos os graus de ensino da educação brasileira e afirmou também que esta hegemonia educacional de esquerda é parte de um plano maior, global, para a tomada do comunismo no mundo. Podemos ver com clareza esta noção no texto abaixo, originalmente publicado no Jornal "O Globo", no ano de 2002, e repostado no atual blog de Olavo de Carvalho:

Denominaram sua filosofia de "teoria crítica" porque se abstinha de propor qualquer remédio para os males do mundo e buscava apenas destruir: destruir a cultura, destruir a confiança entre as pessoas e os grupos, destruir a fé religiosa, destruir a linguagem, destruir a capacidade lógica, espalhar por toda parte uma atmosfera de suspeita, confusão e ódio. Uma vez atingido esse objetivo, alegavam que a suspeita, a confusão e o ódio eram a prova da maldade do capitalismo. [...] Em poucas décadas, o marxismo cultural tornou-se a influência predominante nas universidades, na mídia, no show business e nos meios editoriais do Ocidente. Seus dogmas macabros, vindo sem o rótulo de "marxismo", são imbecilmente aceitos como valores culturais supra ideológicos pelas classes empresariais e eclesiásticas cuja destruição é o seu único e incontornável objetivo. Dificilmente se encontrará hoje um romance, um filme, uma peça de teatro, um livro didático onde as crenças do marxismo cultural, no mais das vezes não reconhecidas como tais, não estejam presentes com toda a virulência do seu conteúdo calunioso e perverso. (CARVALHO , 2020).

Estas ideias foram as bases de influência para o movimento de Miguel Nagib, mesmo havendo um grave rompimento entre mentor e discípulo no ano de 2019 , quando Carvalho acusou o MESP de ser precipitado e chegou a ser agressivo chamando Nagib de "burro" (WALTENBERG, 2020). Apesar destes conflitos, obviamente não exclui que este é um movimento fundado em base conceitual Olavista, que parte de uma lógica conspiracionista que há um pacto silencioso entre todos os professores (ou pela maioria deles) para instaurar um modelo comunista no mundo.

Vimos no tópico anterior que a lógica do MESP se baseia na perspectiva de que os professores são prováveis "doutrinadores" - mesmo sem uma definição clara a respeito tentando roubar dos pais o protagonismo na educação das crianças brasileiras a serviço de um plano escuso. Mas de que modo a perspectiva de um movimento atinge toda uma classe

\footnotetext{
${ }^{4}$ Termos usados por Miguel Nagib para definir Olavo de Carvalho em entrevista à Guilherme Waltenberg da revista Metrópole.
} 
profissional? Através da implementação de leis que atinjam a liberdade docente e da perseguição aos professores, como veremos com mais detalhe neste tópico.

Segundo Lais Semis já foi proposto no Congresso Nacional entre 2014 e 2019 mais de dez anexos e Projetos de Lei (PL) que tem como base o MESP, sendo em sua maioria arquivados, considerados inconstitucionais ou abandonados pelos seus propositores. $O$ último, proposto no começo de 2019 pela deputada Bia Kicis (PSL/DF) ainda está em curso, e é considerado por Miguel Nagib "a versão 2.0" dos anteriores (NAGIB, 2019). O Projeto de Lei 246/19 de Bia Kicis propõe:

Art. $1^{\circ}$ Fica instituído, com fundamento nos artigos 23, inciso I; 24, inciso XV e $\S 1^{\circ}$; e 227, caput, da Constituição Federal, o "Programa Escola sem Partido", aplicável aos sistemas de ensino da União, dos Estados, do Distrito Federal e dos Municípios, em consonância com os seguintes princípios:

IV - ao tratar de questões políticas, socioculturais e econômicas, apresentará aos alunos, de forma justa, as principais versões, teorias, opiniões e perspectivas concorrentes a respeito da matéria;

V - respeitará o direito dos pais dos alunos a que seus filhos recebam a educação religiosa e moral que esteja de acordo com as suas próprias convicções;

Art. $7^{\circ}$ É assegurado aos estudantes o direito de gravar as aulas, a fim de permitir a melhor absorção do conteúdo ministrado e de viabilizar o pleno exercício do direito dos pais ou responsáveis de ter ciência do processo pedagógico e avaliar a qualidade dos serviços prestados pela escola. (BRASIL, 2020).

Analisemos tais questões:

a) Permitir que professores sejam filmados por seus alunos em sua atuação docente - e não me refiro aqui a câmeras institucionais das escolas e universidades - e sim câmeras de posse dos discentes. Isto pode ser extremamente constrangedor e levar a uma exposição violenta e um linchamento virtual, pois muitos destes estudantes ainda estão em processo de amadurecimento, e não conseguem medir as consequências de expor e/ou alterar este material e publica-los nas mídias digitais;

b) A obrigatoriedade do docente de apresentar diversas versões, teorias, opiniões e perspectivas concorrentes a respeito da matéria abre precedentes para que seja colocada em pauta em sala de aula em pé de igualdade ao discurso verificado pela ciência, questões não comprovadas. Por exemplo, quando se fala em opiniões salienta-se ideias como o 
negacionismo histórico ${ }^{5}$, discursos conspiracionistas e anticientíficos, como o movimento antivacina.

c) A proibição de questionamentos as convicções morais e religiosas dos pais, podem ferir os Direitos Humanos, princípios de cidadania e regras legais que devem ser sobrepostos aos valores individuais da família se estes conflitarem.

Assim, este movimento que vê imediatamente o professor como um potencial inimigo, e que pretende colocar em pé de igualdade "opiniões" com questões verificadas pela ciência e "convicções próprias" a valores de cidadania e Direitos Humanos, poderá atingir toda a classe docente e a educação democrática se legalizada através de uma Lei Federal.

Contudo, mesmo ainda estando como projeto, a mera possibilidade da existência desta lei já faz com que seus apoiadores motivem diversos ataques virtuais e pessoais a professores, como verificaremos abaixo.

Em 2017, por exemplo, o vereador por São Paulo e integrante do Movimento Brasil Livre (MBL), Fernando Holliday, passou a fazer visitas surpresas em escolas públicas da sua cidade, no que ele chamou de "Blitz Ideológica". Sob os mesmos argumentos de que os professores são "doutrinadores marxistas", tese defendida por Nagib e Carvalho, o vereador se sentia no direito de invadir salas de aula, selecionadas de maneira aleatórias, instituindo um constante estado de tensão na comunidade docente (ESTADÃO, 2020).

Outro caso que ficou emblemático também no mesmo ano foi o de Ana Carolina Campagnolo que processou sua orientadora de mestrado acusando-a de ter sido preconceituosa contra ela. Campagnolo mobilizou as redes sociais em ataque a professora universitária Marlene de Fáveri, se colocando na postura de uma estudante vítima da doutrinação feminista e marxista das universidades públicas brasileiras após ser reprovada na apresentação de sua dissertação de mestrado. A professora sofreu diversos assédios morais nas redes e passou por inúmeros problemas como ansiedade e depressão. E apesar da justiça reconhecer razão à professora Fáveri, o processo foi suficiente para lançar a popularidade de Campagnolo que se elegeu Deputada Estadual no ano seguinte (FOLHA DE S. PAULO, 2020).

Por fim, temos como exemplo o caso divulgado pelo próprio presidente Jair Bolsonaro, em abril de 2019 , em suas redes sociais, no qual uma estudante confronta a

\footnotetext{
${ }^{5}$ Trata-se da recusa em aceitar uma realidade empiricamente verificável, sendo essencialmente uma ação que não possui validação de um evento ou experiência histórica. Como por exemplo a negação do Holocausto Nazista ou a Escravidão Brasileira.
} 
professora de Gramática. No vídeo a jovem que diz em tom de ameaça: "Todas as suas aulas eu vou gravar e expor na internet, tá bom?" (O GLOBO, 2020). A atitude do presidente de compartilhar em suas redes pessoais denota um claro apoio político a exposição de docentes e motivou seus eleitores a fazerem ataques diretos a professora em questão.

Assim, o discurso de que os docentes são possíveis inimigos, colocados por grandes influenciadores e autoridades, permite e até mesmo incentiva o desrespeito e a violência física contra professores, gerando um contínuo estado de medo entre trabalhadores dessa classe.

Em nome de proteger o Brasil do "Marxismo Cultural", questão indefinida que se sustenta apenas nas próprias falas de quem as profere, a Nova Direita lidera ataques de desmoralização aos docentes através de ideias distorcidas que motivam o ódio a todos os educadores. Isto fere imediatamente as liberdades do docente e as funções da educação referidos por leis próprias (CF/88 e LDB/96), que estudaremos com mais profundidade no tópico posterior.

Lilia Schwarcz nos lembra que "a história da cidadania é (...) uma história de lutas e conquistas relacionadas a diferentes processos" (SCHARWARCZ, 2012, p.21) portanto grande parte da noção de cidadania que desfrutamos hoje, como as compreensões de igualdade de raça, classe e gênero, são consequências das lutas por direitos civis que vieram no pós-guerra, as mesmas lutas combatidas pelos neoconservadores como Kristol e seus seguidores brasileiros. E neste momento ligamos duas pontas deste diálogo.

De um lado o Movimento Escola Sem Partido se estrutura em bases neoconservadoras, que pretende combater as noções de Direitos Humanos e de igualdade - por eles chamados de "marxismo cultural". Por outro lado, a escola brasileira, assegurada pela Constituição e pelas leis, visa defender tais valores. Sendo assim, os discursos de ambos são irreconciliáveis. Se de um lado os professores estão assegurados pela legislação, do outro o MESP se vale da distorção da realidade escolar para jogar com o apoio popular e fazer dele instrumento de ataque a classe docente.

Um dos exemplos mais famosos e nítido desta distorção em busca de ganhar apoio popular é o do "Escola sem Homofobia". Em 2011 o governo Federal através do Fundo Nacional de Desenvolvimento da Educação (FNDE) juntamente com Associação Brasileira de Lésbicas, Gays, Bissexuais, Travestis e Transexuais elaborou materiais a serem entregues para o combate da homofobia na escola. Dentre eles haviam vários vídeos e uma cartilha de formação a professores. Devemos destacar que o material não tinha 
nenhum cunho erótico e seria destinado a alunos do ensino médio, ou seja, adolescente (SOARES, 2020).

Há de se lembrar que cartilha, era didática para formação de professores, que muitas vezes em sua prática não estavam habilitados para uma intervenção adequada em meio a atos homofóbicos em sala de aula. Destaca-se também, que ao contrário do que foi difundido, não havia nenhuma ilustração sexual neste material. Todavia, com a pressão dos conservadores o projeto foi barrado às vésperas de seu lançamento. Este, voltou à tona em 2018 durante a campanha presidencial, quando diversos boatos vinculou o projeto a pedofilia, sexualização da infância, campanha para tornar as crianças homossexuais, e até a mais absurda mentira de que mamadeiras em formato de pênis tinham sido entregues em creches. Isto gerou grande revolta na população que passou a odiar as escolas e seus servidores por acreditarem que estes estavam compactuando com a pedofilia e o abuso sexual de crianças. Uma pesquisa realizada pelo IDEA Big Data/AVAAZ mostra que $84 \%$ dos eleitores do atual presidente da república afirmaram acreditar que instituições de educação infantil entregaram a crianças mamadeiras eróticas (CONGRESSO EM FOCO, 2020). Isto representa que em torno de 48 milhões de adultos no Brasil acreditam que professores e dirigentes escolares são capazes de abusar psicologicamente de seus alunos em nome de cumprir o que chamam de "uma agenda esquerdista".

O professor da Universidade Federal Fluminense, Fernando Penna, estudioso do movimento diz que este explora a falta de conhecimento da população massiva sobre a educação e se baseia numa distorção. Afirma que:

O próprio nome Escola Sem Partido já é bastante enganador. Quando perguntadas se elas são a favor de uma escola sem partido ou de uma escola com partido, a maioria das pessoas optaria pela primeira alternativa. No entanto, esta é uma falsa dicotomia - não é uma escola com ou sem partido que está em jogo. Este movimento defende um projeto de escola que remove seu caráter educacional e transforma os professores em meros transmissores de conhecimento. (PENNA, 2015, p. 295).

Precisamos ressaltar que neste texto estamos tratando de uma forma mais ampla, demonstrando como toda uma classe é atacada e colocada em situação de constante estresse, medo e vigilância devido a uma patrulha ideológica que distorce ideias e se foca em criar uma imagem dos professores como perversos, mentirosos e aliciadores. Porém, devemos lembrar que as historiadoras e historiadores, por lidarem com questões em disputa para validação dos discursos levantados por movimentos de Direita, estão ainda mais vulneráveis nesta relação e por isso são os primeiros a serem atacados. 
Não por acaso existe pelo menos três páginas no Facebook chamados "Meu professor de História mentiu para mim" enquanto não há páginas semelhantes com outras disciplinas das ciências humanas. Também não é coincidência que a professora do vídeo do Porta dos Fundos, acima mencionado, ministre esta matéria. A História constrói sentidos e pode legitimar discursos. Por isso aniquilar a voz de quem a produz em compromisso com a verdade é uma forma de tomar os poderes que ela representa. Ou seja, de forma mais simples, se algum grupo toma para si o poder de escrever a História, sem nenhum compromisso com a ciência ou com a verdade (ao contrário do que fazem os historiadores) podem usá-las para propagar apenas o que Ihes parecer conveniente.

Nesta disputa discursiva os historiadores viram o alvo preferido. Isso pode ser visto, por exemplo, no Twitter oficial do MESP que declara: "professor de História petista é quase pleonasmo vicioso" e que "esses recém-formados professores de História voltam para o sistema de ensino, já na condição de agentes, para infectar o cérebro de novas vítimas" (TWITTER, 2020). A palavra infectar não é usada por acaso. Em outros momentos a mesma página usa a ilustração de insetos para explicar o processo que chamam de "doutrinação". Afirmam: "1) professores militantes põem seus ovos na cabeça dos alunos 2) os ovos eclodem e as larvas devoram o cérebro do hospedeiro zumbificando-o" (TWITTER, 2020).

Assim, a imagem dos professores, em especial de História, passa a ser comparado como algo ruim, sujo e que causa moléstias. Isto muito se deve ao fato de que parte do discurso desta Nova Direita se sustenta na negação de fatos históricos. Marcia Buzalaf nos lembra que o negacionismo histórico "se vale de uma construção narrativa aparentemente verossímil para negar a construção científica da historiografia" $(2019$, p.6) e, assim, numa mão dupla os negacionistas precisam criar ficções históricas e, ao mesmo tempo, deslegitimar a fala dos especialistas. Esta mesma autora nos lembra que:

O desafio que os negacionistas nos apresentam é de outra natureza: na medida em que constroem uma versão fictícia da História e que essa versão produz efeitos políticos, os negacionistas obrigam-nos não somente a refutá-los, mas fazermos uma reflexão sobre a relevância do papel da História e da memória para a educação humanista. (MILMAM Apud BUZALAF, 2019, p. 7).

Assim, os professores de História acabam sendo o alvo preferido nesta onda de ataques a docentes. Esta discussão merece ser aprofundada em outro momento, quem sabe em um futuro artigo. Porém neste trabalho estamos olhando de forma geral como essa postura reacionária em ataque a educação prejudica professores, educandos e todo um projeto de um sistema educacional que objetiva fortalecer a democracia. 
Outro ponto que devemos refletir é sobre o nome escolhido pelo movimento. Quando se fala em "sem partido" leva a crer que defende a escola sem política partidarista. Todavia não seria necessária uma lei específica para isto, uma vez que já é proibida a divulgação de campanhas político partidárias nas escolas e instituições acadêmicas de acordo com a Lei Eleitoral (Art. 37 da Lei 9504/97). O que na verdade o MESP defende é uma escola despolitizada e censurada, que preserve valores de segregação e que ataque a liberdade de cátedra, e para isso se vale de falácias para convencer a população média, pois sabe que a liberdade de pensamento é garantida pelas leis maiores educacionais como veremos com mais cuidado no próximo tópico. Em suma, de um lado os valores constitucionais estão a favor dos professores, de outro a população comum, em geral com baixa participação na vida escolar dos filhos ${ }^{6}$, acreditam que os professores sejam potenciais inimigos e este ódio é estimulado e usado como capital político.

Mais uma vez nos fala Fernando Penna:

Eu venho discutindo um fenômeno que chamei de ódio aos professores, que identifiquei visitando algumas páginas específicas nas redes sociais. Creio que este fenômeno seja mais perceptível no mundo virtual devido à sensação de impunidade que acompanha os comentários de ódio neste espaço, especialmente graças ao recurso dos perfis falsos e ao anonimato. O ódio aos professores é caracterizado por ameaças diretas aos professores de violência física e até de morte. Estas ameaças são realizadas de maneira absolutamente explícita e chocante. Eis um exemplo de um comentário em uma publicação que debatia a questão da docência: "Professor tem que ensinar português e matemática, se passar das matérias relevantes deve ser espancado ou processado". Outro exemplo, este na forma de uma imagem: um homem com uma expressão ameaçadora aponta uma arma de cano duplo na 296 direção do observador, com a seguinte legenda: "Ensine ideologia de gênero para minha filha que você não vai para a cadeia, eu vou para a cadeia". A ameaça de morte está clara. Ao entrar em contato com essa campanha de ódio voltada contra os professores, a pergunta mais pertinente, ao meu ver, é o que está gerando este ódio (PENNA, 2015, p.295-296).

A fala de Fernando Penna só fica mais nítida quando percebemos que em recentemente postagem da página oficial do MESP na rede social Twitter afirmaram: "Ao declarar a inconstitucionalidade de leis que proíbem ideologia de gênero no ensino fundamental, STF pode acabar levando pais a fazer justiça com as próprias mãos para defender a integridade psíquica e moral dos seus filhos" (TWITTER, 2020). Esta frase nos parece uma clara incitação à violência contra professores justificada pela noção distorcida de proteção a crianças e jovens.

${ }^{6}$ Pesquisa realizada a pedido do "Movimento Todos Pela Educação" aponta que apenas $25 \%$ dos pais são comprometidos com a vida escolar de seus filhos. 
Esta postagem se referia a recente decisão do Supremo Tribunal Federal que considerou inconstitucional uma Lei Municipal de Nova Gama - GO que proibia a discussão de Gênero em sala de aula e usava o termo "ideologia de gênero". Com decisão unânime da Corte Suprema e relatoria do Ministro Alexandre de Moraes, foram todos pareceres favoráveis à revogação da mencionada lei. Destes, destacamos a posição do Ministro Alexandre de Moraes que declarou: "ao aderir à imposição do silêncio, da censura e, de modo mais abrangente, do obscurantismo como estratégias discursivas dominantes, de modo a enfraquecer ainda mais a fronteira entre heteronormatividade e homofobia" (SUPREMO TRIBUNAL FEDERAL, 2020).

Esta decisão é considerada uma grande derrota ao MESP, pois esta foi uma das primeiras pautas que Ihes deram visibilidade nacional. Como já mencionamos acima, o MESP e todo o patrulhamento que o acompanha se estrutura em valores neoconservadores que combatem pautas identitárias de inclusão e noções de igualdade assegurado pelos Direitos Humanos. Assim, valores defendidos por movimentos como LGBTQ+ e feminista é sempre um ponto central nos ataques ligados ao grupo.

Como dito, se destacaram inicialmente em 2014 quando houve a tentativa de inclusão da "igualdade de Gênero" nos Planos de Educação. Naquele momento, especialistas designados para elaborar o texto que seria base para Lei 13.005/14 destacaram a importância do "reconhecimento e valorização da diversidade, com vistas à superação da segregação das pessoas com deficiência, das desigualdades sociais, étnicoraciais, de gênero e de diversidade sexual", contudo essa concepção foi duramente atacada por religiosos fundamentalistas e pelo MESP e consequentemente foi eliminado da lei os termos "Gênero" e "Diversidade Sexual".

Em contraposição a tal exclusão, a atual decisão do Supremo permite que a categoria Gênero como conceito que discute a cultura construída em torno do corpo sexuado (SCOTT, 1995, p. 10) e suas multiplicidades sejam conteúdo da educação básica. Esta dura derrota legal, mais uma vez, inflamou os ânimos do MESP, motivando-os a conclamar a ação popular violenta contra os professores no que chamaram "de fazer justiça com as próprias mãos". Vale lembrar que segundo o dicionário de expressões populares significa tal "justiça" significa "punição dada por uma pessoa ou grupo de pessoas sem cumprimento da lei, e baseada em opiniões próprias, com o objetivo de vingança" (DICIONÁRIO INFORMAL, 2020).

Toda essa situação cria um ambiente de medo e tensão entre os profissionais da educação. O jornalista Felipe Betim em matéria para o Jornal "El Pais" afirma que: 
Nunca foi fácil ser professor de escola no Brasil. Paga-se pouco, as jornadas de trabalho são longas, os recursos pedagógicos são escassos e, como se não bastasse, há alunos que recorrem à violência física ou verbal. A essa rotina, desde sempre estressante e mentalmente desgastante, se soma mais recentemente um novo elemento: o ambiente de ódio político no país e a patrulha ideológica promovida pela extrema direita dentro das salas de aula (...) Não existem dados oficiais que retratem essa recente deterioração da saúde dos professores ou essas tensões que acontecem em sala de aula. Porém, uma pesquisa feita pela Associação Nova Escola com 5.000 educadores entre junho e julho de 2018 mostra que $66 \%$ deles já precisaram se afastar do trabalho por questões de saúde. As cifras dão dimensão do ambiente no qual estão inseridos: $68 \%$ sofrem de ansiedade, $63 \%$ relatam estresse e dores de cabeça, 39\% têm insônia, 38\% possuem dores nos ombros e alergias e $28 \%$ apresentam ou apresentaram quadro de depressão. Além disso, $87 \%$ acreditam que o problema é ocasionado ou intensificado pelo trabalho. No ano passado, o Brasil já ocupava o último lugar num ranking internacional que mediu a valorização do professor em 35 países. (BETIM, 2020).

Assim, se não conseguem vencer legalmente, usam de um sistema de linchamento coletivo baseado em inverdades para criar uma esfera de tensão que faz com que os professores temam falar de questões importantes, como pode ser visto no vídeo que mencionamos no início deste trabalho e que satiriza o medo dos professores ao abordarem conteúdos necessários.

Este medo é chamado pelo filósofo e sociólogo Zygmunt Bauman de medo derivado, como explica abaixo:

[...] uma espécie de medo de "segundo grau", um medo, por assim dizer, social e culturalmente "reciclado", ou (...) um "medo derivado" que orienta seu comportamento (...), quer haja ou não uma ameaça imediatamente presente. (...) Uma pessoa que tenha interiorizado uma visão de mundo que inclua a insegurança e a vulnerabilidade recorrerá rotineiramente, mesmo na ausência de ameaça genuína, às reações adequadas a um encontro imediato com o perigo; o "medo derivado" adquire a capacidade da autopropulsão. (BAUMAN, 2008, p.6-10).

Criando então um efeito "panóptico"7, como lembra Michel Foucault, onde os professores temerosos, sem saber de onde vêm as denúncias e as violências (físicas, verbais e morais), se mantêm em constante vigilância e se calam com medo de serem punidos (FOUCAULT, 2010, p.186-216). Assim, o MESP mesmo sem conseguir aprovar

7 O Panóptico foi concebido por Jeremy Bentham como um mecanismo aplicável ao controle do comportamento dos prisioneiros nas prisões e era uma estrutura arquitetônica que permitia os guardas verem os presos, mas os presos não viam os guardas. Desta forma, nunca sabiam se estavam sendo vigiados ou não, logo tinham que aplicar a autocensura para não serem punidos, pois nunca saberiam quando estavam sendo vistos. 
sua lei alcança o seu objetivo, que é criar, no modelo de vigilância e punição, a autocensura e temor dos professores.

Em suma, com tudo o que relatamos acima foi possível notar que de um lado temos a legislação brasileira que se põe em favor à liberdade dos professores e vê a escola como um centro de formação para a cidadania (como veremos no tópico abaixo). De outro temos um grupo de pessoas que discorda destes valores e por isso tenta desvalorizar e violentar a classe docente através de mentiras para ganhar apoio popular. Para isso criam um sistema de constante vigilância - invasões a escolas, exposição na internet, incentivo a filmagem de aulas - e punição, através de ameaças, violências e demissões.

\section{O PAPEL DA EDUCAÇÃO E DO EDUCADOR NA CONSTITUIÇÃO FEDERAL/1988 E NA LEI DE DIRETRIZES E BASES DA EDUCAÇÃO (LDB/96):}

Carlos Rodrigues Brandão afirma que "ninguém escapa da educação". E se pensarmos na educação como um processo formativo lato, todos estão inclusos neste percurso infinito de aprender e ensinar. Este autor afirma:

Em casa, na rua, na igreja ou na escola, de um modo ou de muitos todos nós envolvemos pedaços da vida com ela: para aprender, para ensinar, para aprender e ensinar. Para saber, para fazer, para ser ou para conviver, todos os dias misturamos a vida com a educação. Com uma ou com várias: educação? Educações. (p. 2, 1989).

Porém, quando falamos em educação neste trabalho nos referimos ao processo formal, que envolve a escolarização de indivíduos, realizado de modo massivo no contemporâneo, obedecendo regras e metodologias. Sabemos, porém, que a educação formal nem sempre foi assim. Ao longo da História da humanidade o acesso a uma instrução através de professores e tutores sempre foi um privilégio de uma minoria elitista, e somente a partir da Revolução Industrial, com a expansão do Capitalismo Liberal e da urbanização, que foi pensado pela primeira vez na universalização do ensino e a na ideia de se construir escolas para toda a população (ARANHA, 2006, p.200) Este processo se iniciou na Europa entre os século XVIII e XIX, mas no Brasil estes conceitos só viriam de maneira mais enfática e estruturada no século XX (GHIRALDELLI, 2001, p. 29-30). De lá para os dias de hoje, muito foi pensado sobre o papel da educação na sociedade e a quem deveria ser atribuído sua responsabilidade. 
Não cabe aqui neste breve trabalho traçar uma linha da grande trajetória das disputas filosóficas/pedagógicas e dos conceitos que transcorreram no Brasil e no mundo ao longo do século XX e XXI, porém devemos lembrar fundamentalmente que a educação é um processo histórico, que se atêm ao movimento da sociedade. Assim as percepções de mundo influenciam na educação, do mesmo modo que a educação gera influência nas percepções de mundo, em um processo contínuo e dinâmico.

Nosso atual modelo de educação, assegurado pela Constituição Federal, entende que a formação é um processo amplo que envolve Estado, família e comunidade, sendo dever dos dois primeiros. E esta parceria visa o pleno desenvolvimento da pessoa e se baseia na Declaração Universal dos Direitos Humanos que diz em seu artigo 26:

1. Todos os seres humanos têm direito à educação. A educação será gratuita, pelo menos nos graus elementares e fundamentais. A educação elementar será obrigatória. A educação técnica-profissional será acessível a todos, bem como a educação superior, está baseada no mérito.

2. A educação será orientada no sentido do pleno desenvolvimento da personalidade humana e do fortalecimento do respeito pelos direitos humanos e pelas liberdades fundamentais. A educação promoverá a compreensão, a tolerância e a amizade entre todas as nações e grupos raciais ou religiosos, e coadjuvará as atividades das Nações Unidas em prol da manutenção da paz.

3. Os pais têm prioridade de direito na escolha do género de educação que será ministrada aos seus filhos. (ONU, 2020)

Podemos verificar que no item 3 afirma-se que os pais têm prioridade de escolher a educação a ser dada aos filhos, contudo, há de se lembrar que estas escolhas não podem ferir ou contrapor o ponto anterior. Desta forma a educação não é incondicionada a "opinião dos pais" como lembra o texto do Projeto de Lei do Escola Sem Partido, mas sim uma parceria entre pais e Estado, visando alcançar os Direitos Humanos, a igualdade e os direitos fundamentais.

Isso também pode ser notado em nossa Constituição Federal que diz:

Art. 205. A educação, direito de todos e dever do Estado e da família, será promovida e incentivada com a colaboração da sociedade, visando ao pleno desenvolvimento da pessoa, seu preparo para o exercício da cidadania e sua qualificação para o trabalho. (BRASIL, 2020.)

Assim, destaca que um dos maiores objetivos da educação é promover o exercício da cidadania, juntamente com o desenvolvimento da pessoa e formação para o trabalho. Logo o Estado é parte fundamental neste processo. Ou seja, a família não terá prioridade sobre esta formação se ela não conseguir atender as demandas de criar um sujeito capaz 
de colaborar com a sociedade ou que esteja preparado para o exercer um papel de cidadão que respeita os seus deveres e direitos. Assim, independente da opinião dos pais, os professores têm obrigação moral e legal de formar e ensinar questões que vão ao encontro dos Direitos Humanos, das noções de cidadania e das lógicas da ciência. Como mesmo lembra José Manuel Moran a "educação é a soma de todos os processos de transmissão do conhecido, do culturalmente adquirido e de aprendizagem de novas ideias, procedimentos e soluções desenvolvidos por pessoas, grupos, instituições" (2011, p. 16)

Este mesmo autor menciona cabe a escola o duplo papel de Ensino e Educação, junto com os pais e com a comunidade. Destaca:

Ensino e educação são conceitos diferentes. No ensino organiza-se uma série de atividades didáticas para os alunos a compreender áreas específicas do conhecimento (ciências, história, matemática). Na educação o foco, além de ensinar, é ajudar a integrar ensino e vida, conhecimento e ética, reflexão e ação, a ter uma visão da totalidade. Educar é ajudar a integrar todas as dimensões da vida, a encontrar nosso caminho intelectual, emocional, profissional, que nos realiza e que contribua para modificar a sociedade que temos. (MORAN, MASETTO \& BAHRENS, 2000, p. 12).

Desta maneira, pais e Estado (através da escolarização) devem caminhar lado a lado ao encontro de uma educação universal em igualdade de acesso, mas que respeite as particularidades e individualidades de cada grupo, desde que estas individualidades não firam princípios de solidariedade social, cidadania e Direitos Humanos.

Um exemplo desta questão é o ensino de Gênero nas escolas (que tem como base eliminar as violências homofóbicas/transfóbicas e as demais discriminações em relação a diversidade sexual, as desigualdades sociais/políticas/salariais entre homens e mulheres). Assim quando os pais ou o MESP tenta combater esta formação, eles ferem imediatamente princípios assegurados em tratados da Organização das Nações Unidas que expressam sobre a equidade de Gênero e Sexualidade ${ }^{8}$.

Lembramos que é fundamental na formação humana a participação da Família e da Escola no desenvolvimento pleno do indivíduo. Uma parceria entre pais e professores cria crianças mais críticas, criativas e capazes de se inserir no mundo adulto. Como nos lembra Cynthia Oliveira e Clasy Marinho-Araújo que dizem:

Escola e família têm suas especificidades e suas complementariedades. Embora não se possa supô-las como instituições completamente independentes, não se pode perder de vista suas fronteiras institucionais,

8 Declaração e Plataforma de Ação da IV Conferência Mundial Sobre a Mulher (Pequim, 1995); Objetivo n 5 dos Objetivos do Desenvolvimento Sustentável da ONU (2015). 
ou seja, o domínio do objeto que as sustenta como instituições. Esses dois sistemas têm objetivos distintos, mas que se interpenetram, uma vez que "compartilham a tarefa de preparar as crianças e os jovens para a inserção crítica, participativa e produtiva na sociedade". (OLIVEIRA \& MARINHOARAUJO, 2010, p.191).

Assim, essa mobilização de ódio aos professores, feito através de mentiras, com objetivo eleitoral, que tem como meta desestabilizar a busca pela igualdade de gênero, classe e raça, criam uma ruptura muito prejudicial entre família e professores. Pessoas que deveriam ser vistas como aliadas passam a ser tidas como inimigas. Gerando uma rachadura que poderá ser sentida na vida adulta do educando, além de causar inúmeros estragos na vida de toda uma classe profissional, criando medo, desestimulo e insegurança.

Devemos lembrar que o MESP fere também a autonomia docente, chamada de "Liberdade de Cátedra", que nada mais é que um conjunto de direitos pautado na liberdade de expressão, que assegurada no artigo 206 da CF/88 que garante "autonomia de aprender, ensinar, pesquisar e divulgar o pensamento, a arte e o saber" (BRASIL, 2020). Enfim é a possibilidade de autodeterminação que o professor tem em sala de aula para tratar de diversos assuntos que entenda como importante para o ensino.

O jurista Fabrício Veiga Costa ao analisar a inconstitucionalidade de um dos Projetos de Lei apresentado pelo MESP diz que a formação deve "estimular o pensamento crítico dos discentes no que atine às questões culturais, sociais, políticas, econômicas, além de atender as demandas de cada microrregião do país onde se encontram as instituições" e deve atender ainda "a inclusão das pessoas socialmente marginalizada". Desta maneira a "liberdade de cátedra é fundamental ao docente para que tenha legitimidade na identificação dos problemas sociais existentes e, assim, fomentar o debate crítico em sala de aula" (p.380, 2018). Assim ele afirma que:

O papel do professor (...) remete a uma postura ativa, dialética, política e ética, fazendo com que este educador tenha um compromisso permanente com a vida dos alunos, assim como com a autonomia de seus educandos, oportunizando espaços onde a liberdade possa ser exercida de forma criativa e espontânea. (COSTA, 2018, p.380-381).

Em outras palavras, os professores podem sim discutir ideias sobre a sociedade e emitir suas opiniões sobre elas. Todavia, devemos destacar que assim como a liberdade de expressão, a de cátedra que permite ao docente autonomia para expressar seus pensamentos sobre as relações sociais, é também limitada para que não afronte valores fundamentais como o direito a igualdade ou que através dela se pratique discriminação, 
exclusão, racismo, homofobia, apologia ao crime, sexismo e etc. E os professores que cometerem tais atos devem responder judicialmente através das legislações já existentes como o Código Penal. Também é preciso deixar explícito que opinião política se difere de apologia político-partidária - apoiar um político ou um partido em sala de aula - o que é, como já foi dito, proibido pela lei eleitoral.

Fernando Penna destaca que o MESP - através de seus projetos de leis - exigem um professor que não construa conexões entre os saberes acadêmicos e a sociedade, e que não crie diálogos com pensamentos intelectuais e a realidade social. Este autor, que defende uma escola democrática, destaca o quão é absurda ideia de que o professor deve ser um mero reprodutor de conteúdos em sala de aula, sem uma interação profícua com seus educandos.

[O MESP] defende que "professor não é educador", mas apenas um instrutor que deve se limitar a transmitir "a matéria objeto da disciplina" sem discutir o que acontece na realidade em que os alunos estão inseridos. Caso contrário, estaria usurpando um direito dos pais. Trata-se de uma interpretação equivocada da Convenção Americana sobre Direitos Humanos, que garante aos pais o direito de que seus filhos recebam educação moral e religiosa de acordo com as suas convicções no espaço privado da família, vedando ao Estado qualquer medida restritiva que limite a sua liberdade de mudar ou conservar sua religião ou suas crenças (artigo 12). Os professores realmente não têm o direito de coagir os alunos a mudarem as suas crenças, mas os alunos e seus pais tampouco têm o direito de se negarem a dialogar com outros valores no espaço público da escola. Ao tentar tornar a educação uma questão privada, responsabilidade exclusiva das famílias, o movimento "Escola sem partido" contraria diretamente a Constituição brasileira, que em seu artigo 205. (PENNA, 2020).

Temos que destacar que a Liberdade de Cátedra não foi assegurada apenas na última Constituição Brasileira. Este termo foi expresso pela primeira vez na Constituição da República dos Estados Unidos do Brasil em 16 de julho de 1934, no governo de Getúlio Vargas, e tornou a aparecer na Constituição de 1946. Em 1967, em maior amplitude a descrição constitucional inseriu-a no inciso VI, do $\S 3^{\circ}$ do art. 168 , no qual se repetia a expressão é garantida a liberdade de cátedra. Na atual Constituição Federal (de 1988) aparece em seu artigo $3^{\circ}$, inciso II, que diz "constituem objetivos fundamentais da República Federativa do Brasil construir uma sociedade livre, justa e solidária" (BRASIL, 2020). Ainda no texto constitucional, o artigo $5^{\circ}$ prevê que todos são iguais perante a lei e garante entre outros o direito à liberdade, resguardando em especial a liberdade de manifestação de 
pensamento e a liberdade de expressão da atividade intelectual, artística, científica e de comunicação.

Também o artigo 206 da Carta Magna relata especificidades ao ensino, prevê Liberdade para o ensino e aprendizagem, de pesquisa e divulgação do conhecimento dentro de uma pluralidade de ideias e concepções pedagógicas com garantia e padrão de qualidade. (BRASIL, 2020).

A Lei de Diretrizes e Bases da Educação (LDB/96) estabelece, em seu artigo primeiro que os processos formativos se desenvolvem "na vida familiar, na convivência humana, no trabalho, nas instituições de ensino e pesquisa, nos movimentos sociais e organizações da sociedade civil e nas manifestações culturais", ou seja, é muito importante a formação de indivíduos em seus grupos de pertencimento (BRASIL, 2020). E no artigo seguinte repete a constituição falando sobre as responsabilidades da família e do Estado. Lembrando mais uma vez que não existe uma hierarquia entre ambos, e sim a responsabilidade recíproca na formação humana e cidadã dos indivíduos.

O artigo terceiro da LDB/96 se pauta principalmente no direito à igualdade, a liberdade de aprender, ensinar e pesquisar, na divulgação do pensamento e respeito a liberdade em consonância com os princípios constitucionais previstos no Art. 206 da Constituição Federal de 1988, que dispõe que o ensino será ministrado com base na "Liberdade de aprender, ensinar, pesquisar e divulgar o pensamento, a arte e o saber" assim como no "pluralismo de ideias e de concepções pedagógicas, e coexistência de instituições públicas e privadas de ensino" (BRASIL, 2020).

Desse modo, se pode ver que há um amplo arcabouço legislativo que determina os objetivos da educação no Brasil e estes contradizem imediatamente as questões centrais do Movimento Escola Sem Partido. Não por acaso, inúmeras vezes os projetos baseados no MESP foram rejeitados em comissões do Congresso Nacional antes mesmo de ir a plenária. Também se pode ver que tais projetos ferem inclusive garantias de Direitos Humanos, pois a própria $\mathrm{ONU}^{9}$ se manifestou contra eles por considera-los perigosos a Democracia. Desta maneira, os exemplos legais que elencamos acima corrobora com nossa tese de que, como não recebe apoio legal, o MESP se vale de outros recursos. Dentre eles a distorção de fatos e a criação de mentiras que incentivem o ódio popular

9 Comunicado das Relatorias Especiais do Alto Comissariado de Direitos Humanos da Organização das Nações Unidas (ONU) publicado em 13 de abril de 2017 disponível no site oficial ONU/ Direitos Humanos 
contra professores e também uma tentativa de impor uma noção de neutralidade no ambiente escolar.

Assim, na conclusão desta análise, entendemos que a escolarização massiva tal qual conhecemos nos dias de hoje nasceu em momento específico da História, quando o capitalismo se estendia da Europa para o resto do mundo. Logo, nasceu de uma necessidade pontual - portanto a partir de um discurso específico - e se estruturou como meio de difusão de conceitos e pensamentos através do acolhimento dos filhos dos proletários. Mas o que cabe ser dito aqui, acima de tudo, é que o modelo contemporâneo de escola nasceu de um propósito social e partiu de uma visão de mundo específica. Em outras palavras, a escola não pode ser neutra, porque nunca foi. Como qualquer ato da sociedade, é tomada de proposito e intenção. Não negamos que estes propósitos se transformaram ao longo de quase três séculos, no entanto, não é possível pedir a neutralidade do processo de escolarização, como propõe o MESP. Porém acreditamos que essa falsa neutralidade que exigem, na verdade nada mais é que uma tentativa de eliminação de discursos contrários aos pensamentos reacionários sustentados pelos grupos políticos a quem servem, que chamamos de maneira simplista de Nova Direita. Pois como já foi dito, sustentam um discurso irreconciliável - baseadas em lógicas neoconservadoras e reacionárias - com os padrões de uma escola democrática, cidadã e amparada nas lógicas humanísticas que a educação brasileira se propõe a ser. Assim, ao exigirem "neutralidade" estão pedindo na verdade o silenciamento dos professores que atuam numa tentativa de educação cidadã. O que realmente pedem não é uma escola sem partido, mas sim uma escola sem as posições políticas que lhes desagradam. Buscam equiparar opiniões à ciência, e, convicções pessoais à normas internacionais sobre direitos e deveres sociais.

O autor Gaudêncio Frigotto que diz:

Os arautos e mentores da "Escola Sem Partido" avançam num território que historicamente desembocou na insanidade da intolerância e eliminação de seres humanos sob o nazismo, o fascismo e similares. Uma proposta que é absurda e letal pelo que manifesta e pelo que esconde. $O$ que os projetos que circulam no Congresso Nacional, em Câmaras Estaduais Municipais, em alguns casos como Alagoas, já aprovados, cuja matriz é a "Escola Sem Partido" liquidam a função docente no que é mais profundo - além do ato de ensinar, a tarefa de educar (FRIGOTTO, 2016, p.11).

O filosofo francês Michel Foucault diz que "o discurso é o objeto de desejo" e que "não é simplesmente aquilo que traduz as lutas ou sistemas de dominação, mas aquilo pelo que se luta" (FOUCAULT, p.10, 2012). Desta forma, a Nova Direita luta para tomar o 
discurso, e para isso usa estratégias semelhantes em diversos braços de uma agenda única, sendo um deles o MESP, pois entendem que a escola é espaço de formação das novas gerações, e é por isso um ponto fundamental para tomada de poder.

\section{REFLEXÕES FINAIS}

Então para finalizar nossa análise, notamos que o Movimento Escola Sem Partido usa de meios escusos uma vez que não se sustenta legalmente, e se vale de inverdades para motivar a reação popular colocando os docentes no centro de ataque. Este processo é extremamente prejudicial a ideia de uma educação livre e democrática, e que por isso o MESP ou qualquer forma semelhança de posicionamento deve ser combatido. Pois para além das máculas que representam a todo o sistema educacional e ao estado democrático, ainda implica consequências irreparáveis a todos os indivíduos envolvidos nesta cadeia. Primeiro, aos professores, que acuados se sentem coagidos e limitados em sua atuação docente. E que diante da imensa desvalorização que já enfrentam estruturalmente, se veem obrigados a lidar com mais um problema, o da perseguição ideológica que pode leva-los a verdadeiros linchamentos virtuais, ameaça à integridade física e a segurança financeira. Esta constante ameaça agrava quadros de desgaste emocional, aumentado o medo, o estresse e ansiedade no exercício da atividade do educador. Também atinge imediatamente os educandos, que se veem prejudicados pela ruptura da relação família-escola, fundamental para a formação do indivíduo em sua plenitude.

Por isso, estes movimentos, com seus discursos de ataque aos docentes e tentativas de silenciamento, que se espalham na velocidade das Fake News, devem ser pensados pelos intelectuais e trabalhadores da educação para que assim sejam combatidos. E apesar da epígrafe do Lenine, que fala do medo como algo tão fortes que não nos deixa andar, não devemos nos permitir ser tomado por ele. Quando falo de nós, não me refiro ao professor, indivíduo, limitado, isolado e dependente do empregador, que muitas vezes por segurança opta pelo silêncio. Falo de nós como categoria, grupo social conectados por uma profissão que agora é mais do que nunca atacada. Isto remete mais uma vez a fala de Fernando Penna, pesquisador e militante pela educação democrática, 
e um dos maiores nomes no combate a censura na escola. Ele diz em entrevista ${ }^{10}$ que para resistirmos a estes ataques devemos nos preparar para termos legitimidade acadêmica, conhecer a legislação educacional (pois elas são importantes aliadas na garantia dos nossos direitos) e acima de tudo manter "redes de sociabilidade" das mais variadas formas, sejam através de sindicatos, grupos de pesquisa/estudo ou movimento social.

Então, ao encerrar este trabalho esperamos que este artigo seja reflexão sobre a difícil condição docente no Brasil em meio ao crescimento de uma nova e extrema Direita. E que ele possa trazer uma visibilização a perseguição política que gera agressões causadoras de profundas sequelas emocionais em uma classe profissional, e que prejudica imensamente a formação de toda uma geração. Mas também pretendemos lembrar que estes ataques fazem parte de algo maior, que não é apenas uma ameaça para esta classe, mas para toda Democracia. E acima de tudo, queremos que este artigo seja parte de uma rede de sociabilidade, na qual se possa discutir e se fortalecer mutuamente, para que possamos resistir em meio a um sistema que tenta nos impor o silêncio através do medo e da violência.

\section{REFERÊNCIAS}

ARANHA, Maria Lúcia. História da Educação e da Pedagogia. Geral e Brasil. São Paulo: Moderna, 2006.

BAUMAM, Zygmunt. Medo Líquido. Rio de Janeiro: Zahar, 2008.

BETIM, Felipe. Campanha "anti-doutrinação" contra professores eleva estresse em sala de aula. Disponível em < https://brasil.elpais.com/brasil/2019/05/14/politica/1557790165_316536.html> Consultado em 20 mai. de 2020.

BRASIL. Constituição Federal de 1988. Disponível em <http://www.planalto.gov.br/ccivil_03/constituicao/constituicao46.htm> Consultado em 28 abr. de 2020.

BRASIL. Lei de Diretrizes e Bases da Educação. Disponível em <http://www.planalto.gov.br/ccivil_03/leis//9394.htm> Consultado em 20 abr. de 2020.

BRASIL. Lei Eleitoral. Disponível em < http://www.planalto.gov.br/ccivil_03/leis//9504.htm>. Consultado em 15/04/2020.

10 Canal do Youtube GEPEG Grupo de Estudos e Pesquisa em Gênero da Faculdade de História da Universidade Federal de Goiás. 
BRASIL. Câmara dos Deputados. PL 246/19. Disponível em < https://www.camara.leg.br/proposicoesWeb/fichadetramitacao?idProposicao=2190752> Consultado em 20 abr. de 2020.

BRASIL. Supremo Tribunal Federal. Lei municipal que proíbe ensino sobre questões de gênero é inconstitucional. Disponível em < http://www.stf.jus.br/portal/cms/verNoticiaDetalhe. asp?idConteudo=442331> Consultado em 20 abr. de 2020.

BRANDÃO, Carlos Rodrigues. O que é educação? São Paulo: Brasiliense, 1989.

BUZALAFI, Marcia. Revisionismo ou Negacionismo? A Ditadura Civil-militar no Filme "1964 - o Brasil entre armas e livros (2019)". Disponível em

<http://portalintercom.org.br/anais/nacional2019/resumos/R14-2116-1.pdf> Consultado em 19/04/2020.

CARVALHO, Olavo. Do Marxismo Cultural. Disponível em: < https://olavodecarvalho.org/do-marxismo-cultural/> Consultado em 05 abr. de 2020.

CONGRESSO EM FOCO. Pesquisa mostra que $\mathbf{8 4 \%}$ dos eleitores acreditam no Kit Gay. Disponível em <https://congressoemfoco.uol.com.br/eleicoes/pesquisa-mostra-que84-dos-eleitores-de-bolsonaro-acreditam-no-kit-gay/> Consultado em 10 abr. de 2020.

COSTA, Fabrício. Liberdade de cátedra do docente nos cursos de bacharelado em Direito: um estudo crítico da constitucionalidade do projeto de lei Escola sem Partido. Rev. Jurídica. vol. 01, n. 50, pp. 374-397, Curitiba, 2018.

DICIONÁRIO INFORMAL. Fazer Justiça com as próprias mãos. Disponível em <https://www.dicionarioinformal.com.br/fazer\%20justi\%C3\%A7a\%20com\%20as\%20pr\%C 3\%B3prias\%20m\%C3\%A3os/> Consultado em 25 mai. de 2020.

ESCOLA SEM PARTDO, 2019. 1 vídeo (2min). Publicado pelo canal Porta dos Fundos. Disponível em: < https://www.youtube.com/watch?v=tNxCmR5OWe8>. Acesso em: 25 ago. 2021.

ESTADAO. Educação. Vereador Fernando Holiday faz blitz em escolas. Disponível em <https://educacao.estadao.com.br/noticias/geral,vereador-fernando-holiday-faz-blitz-emescolas-para-verificar-doutrinacao,70001726796> Consultado em abril de 2020.

FOLHA DE SÃO PAULO. Briga judicial entre professora e aluna ilustra racha político no país. Disponível em < https://www1.folha.uol.com.br/ilustrissima/2018/10/briga-judicialentre-professora-e-aluna-ilustra-racha-politico-no-pais.shtml> Consultado em abril de 2020.

FOUCAULT, Michel. Vigiar e Punir. Nascimento da prisão. Petrópolis: Vozes, 2010.

FOUCAULT, Michel. A ordem do discurso. São Paulo: Loyola, 2012. 
FRIGOTTO, Gaudêncio. Escola Sem Partido: Imposição da mordaça aos educadores. Rev. E-Mosaicos. Rio de Janeiro, v. 5, n. 9, pp.11-13, 2016.

GEPEG (Grupo de Estudos e Pesquisa em Gênero). Disponível em $<$ https://www.youtube.com/watch?v=ATvdzgMkVnA>. Consultado em 10 jun. 2020.

GHIRALDELLI, Paulo. Filosofia e História da educação brasileira. Barueri: Manole, 2003.

MIGUEL, Luís Felipe. Reemergência da direita brasileira. In: GALLEGO, Esther Solano. O ódio como política. A reinvenção das Direitas no Brasil. São Paulo: Boitempo, 2018.

MORAN, José Manuel. A educação que desejamos: novos desafios e como chegar lá. 5. ed. Campinas-SP: Papirus, 2011.

MORAN, José Manuel. MORAN, José Manuel. MASETTO, Marcos. BAHRENS, Marilda. Novas tecnologias e mediação pedagógicas. Campinas-SP: Papirus, 2000.

ORGANIZAÇÃO DAS NAÇÕES UNIDAS (ONU). Declaração Universal dos Direitos Humanos. Disponível em <

https://www.ohchr.org/EN/UDHR/Documents/UDHR_Translations/por.pdf> Consultado em abril de 2020.

ORGANIZAÇÃO DAS NAÇÕES UNIDAS (ONU). Comunicado das Relatorias Especiais do Alto Comissariado de Direitos Humanos. Disponível em $<$

https://www.ohchr.org/Documents/Issues/Opinion/Legislation/OLBrazileducation.pdf> Consultado em 10 jun. 2020.

O GLOBO. Bolsonaro divulga vídeo de aluna que filmou professora. Disponível em < https://oglobo.globo.com/sociedade/bolsonaro-divulga-video-de-aluna-que-filmouprofessora-em-aula-23628113> Consultado em abril de 2020.

OLIVEIRA, Cynthia. MARINHO-ARAÚJO, Claisy. A relação família-escola: intersecções e desafios. Rev. Estudos de Psicologia, Campinas, v. 27, p.99-108, 2010.

PENNA, Fernando. Entrevista com Fernando Penna. Rev. Movimento. Rio de Janeiro, v.3, ano 2, p.294-301, 2015.

PENNA, Fernando. Proibido educar? Disponível em <

https://web.archive.org/web/20161015035346/http://rhbn.com.br/secao/educacao/escolasem-ensino> Consultado em maio de 2020.

REIS, Toni. EGGERT, Edla. Ideologia de gênero: uma falácia construída sobre os planos de educação brasileiros. Rev. Educ. Soc., Campinas, v. 38, nº. 138, p.9-26, 2017.

ROCHA, Camila. O boom da Nova Direita: financiamento ou militância? In: GALLEGO, Esther Solano. O ódio como política. A reinvenção das Direitas no Brasil. São Paulo:

Boitempo, 2018. 
SAFATLE, Vladimir. Introdução. In: GALLEGO, Esther Solano. O ódio como política. A reinvenção das Direitas no Brasil. São Paulo: Boitempo, 2018.

SCHWARCZ, Lilia. BOTELHO, André. Cidadania e Direitos: aproximações e relações. In: SCHWARCZ, Lilia. BOTELHO, André Cidadania, um projeto em construção. Minorias, justiça e direitos. São Paulo: Claro Enigma, 2016.

SCOTT, Joan. Gênero: uma categoria útil de análise histórica. Educação e Realidade, v. 16, n.2, jul/dez 1990.

SEMIS, Lais. Entenda o novo projeto "Escola Sem Partido" que tramita na Câmara Nacional. Disponível em <https://novaescola.org.br/conteudo/15818/entenda-o-novoprojeto-do-escola-sem-partido-que-tramita-na-camara>. Consultado em 20 abr. de 2020.

SOARES, Wellington. Conheça o Kit Gay vetado pelo governo federal em 2011. Disponível em <https://novaescola.org.br/conteudo/84/conheca-o-kit-gay-vetado-pelogoverno-federal-em-2011> Consultado em 10 mar. de 2020.

TEIXEIRA, Carlos G. Poggio. O pensamento neoconservador em política externa nos Estados Unidos. Dissertação (mestrado em Relações Internacionais) - Faculdade de Relações Internacionais, Pontifícia Universidade Católica. São Paulo, p. 128. 2007.

THE NOITE. Intérpretes: Danilo Gentili, Miguel Nagib. São Paulo: 2016. Vídeo (27 min.). Disponível em <https://www.youtube.com/watch?v=wkBBW91jVEA>. Consultado em 20 abr. de 2020.

TWITTER. Movimento Escola sem Partido. Postado em 27 de abril de 2020. Disponível em de <https://twitter.com/escolasempartid/status/1254957272410853376> Consultado em 15 jun.de 2020.

TWITTER. Movimento Escola sem Partido. Postado em 19 de abril de 2019. Disponível em de < https://twitter.com/escolasempartid/status/1118632195344740352> Consultado em 15 jun.de 2020.

WALTENBERG, Guilherme. "Não quero pregação anticomunista" diz Nagib, do Escola Sem Partido. Disponível em: <https://www.metropoles.com/brasil/politicabrasil/nao-quero-pregacao-anticomunista-diz-nagib-do-escola-sem-partido>. Consultado em 20 abr. de 2020.

\section{NOTAS}

TÍTULO DA OBRA

O MOVIMENTO ESCOLA SEM PARTIDO E A POPULARIZAÇÃO DO ÓDIO AOS DOCENTES.

NEIDE CÉLIA FERREIRA BARROS
MESTRA
Instituto Federal de Goiás, História, Goiânia-GO, Brasil
neidecelia@gmail.com
ORCID 0000-0001-9336-0168 (D)

Endereço de correspondência do principal autor 
Endereço para correspondência indicando Av. Euclides da Cunha, Area E, Cond. Yes Buriti, ap. 804 B - St. Cruzeiro do Sul, Aparecida de Goiânia CEP 74.917-195

\section{LICENÇA DE USO}

Os autores cedem à Em Tese os direitos exclusivos de primeira publicação, com o trabalho simultaneamente licenciado sob a Licença Creative Commons Attribution 4.0 Internacional (CC BY). Estra licença permite que terceiros remixem, adaptem e criem a partir do trabalho publicado, atribuindo o devido crédito de autoria e publicação inicial neste periódico. Os autores têm autorização para assumir contratos adicionais separadamente, para distribuição não exclusiva da versão do trabalho publicada neste periódico (ex.: publicar em repositório institucional, em site pessoal, publicar uma tradução, ou como capítulo de livro), com reconhecimento de autoria e publicação inicial neste periódico.

\section{PUBLISHER}

Universidade Federal de Santa Catarina. Programa de Pós-Graduação em Sociologia Política. Publicado no Portal de Periódicos UFSC. As ideias expressadas neste artigo são de responsabilidade de seus autores, não representando, necessariamente, a opinião dos editores ou da universidade.

\section{HISTÓRICO}

Recebido em: 20 de novembro de 2020.

Aprovado em: 12 de julho de 2021 